\section{Suppressing Pecan Aphid Populations Using Potassium Nitrate Plus Surfactant Sprays}

\author{
Bruce W. Wood and Jerry A. Payne \\ U.S. Department of Agriculture, Agricultural Research Service, Southeastern \\ Fruit and Tree Nut Research Laboratory, 111 Dunbar Road, Byron, GA 31008 \\ Michael T. Smith \\ U.S. Department of Agriculture, Agricultural Research Service, Jamie Whitten \\ Delta States Research Center, P.O. Box 346, Stoneville, MS 38776
}

Additional index words. Carya illinoinensis, alternate bearing, biological control, IPM, plant nutrition, soaps, Monellia caryella, Monelliopsis pecanis

\begin{abstract}
A 4-year field study on pecan [Carya illinoinensis (Wangenh.) K. Koch] provided indirect support of the supposition held by some U.S. pecan growers that air-blast foliar sprays of potassium nitrate $\left(\mathrm{KNO}_{3}\right)$ plus surfactant enhances nut yield. While these treatments did not measurably influence yield components, foliar $K$ nutrition, or net photosynthesis, they did suppress "yellow-type" aphid populations. While air-blast sprays of water alone suppressed aphid populations, the inclusion of $\mathrm{KNO}_{3}$ plus surfactant provided an additional level of suppression.
\end{abstract}

Some U.S. pecan growers spray trees with potassium nitrate $\left(\mathrm{KNO}_{3}\right)$, sometimes mixed with a surfactant, to increase foliar uptake of $\mathrm{K}$, with the objective of increasing nut yields. The application of potassium nitrate/surfactant (PNS) sprays to orchards is not standardized. The spray may or may not be tank-mixed with any one of several fungicides when used on disease-prone cultivars in the southeastern United States and may be used without a fungicide in the less humid portions of the pecan belt. While there is considerable variance in application protocol, the following characteristics generally delineate the practice when PNS is not mixed with fungicides. Potassium nitrate is applied at $0.5 \%$ to $1 \%$ solutions (w/w) with a surfactant applied at $0.15 \%$ $(w / w)$. The timing, frequency of air-blast sprays, and types of surfactants used also are variable; however, foliar $\mathrm{KNO}_{3}$ sprays with a low-cost trisodium phosphate-based surfactant periodically applied throughout most of the spring and summer appear to be typical. While there is indirect evidence that this cultural practice may be justified-because of the possible effect of $\mathrm{KNO}_{3}$ on leaf nutrition (Smith, 1991) or of aphid populations on yield (Dutcher et al. 1984; Tedders and Wood, 1985; Wood et al., 1987) — to our knowledge, no attempt has been made to objectively assess the efficacy of the practice. In fact, observations by Smith et al. (1987) indicate that K applied as either $\mathrm{KNO}_{3}$ or $\mathrm{K}_{2} \mathrm{SO}_{4}$ to mature pecan foliage does not materially increase leaf

\footnotetext{
Received for publication 25 Oct. 1994. Accepted for publication 9 Mar. 1995. The cost of publishing this paper was defrayed in part by the payment of page charges. Under postal regulations, this paper therefore must be hereby marked advertisement solely to indicate this fact
}

$\mathrm{K}$ levels, thus raising doubts as to the validity of the practice on the basis of $\mathrm{K}$ nutrition. However, there may be a basis for use based on its influence on pests. For example, metallic salts of heavy metals, such as K, can be toxic to certain arthropods (Moorthy and Srinivason, 1989) and certain surfactants exhibit biocidal activity (Condrashoff, 1986; Hastings et al., 1986; Miller, 1989; Moore et al., 1979; Parry et al., 1989); therefore, air-blast sprays of a mixture of $\mathrm{KNO}_{3}$ and a surfactant may possibly influence nut yield via suppression of aphid populations, since these pests can greatly impact yields (Wood et al., 1987).

Our study addresses the validity of the supposition that early season spraying of pecan solely with PNS increases nut yield. This hypothesis was evaluated by assessing the influence of these spray treatments on 1) nut production, kernel quality, or both; 2) leaf $\mathrm{K}$ content; 3) leaf photosynthetic activity; and 4) aphid population levels.

Nut production and kernel quality. In an effort to characterize the grower practice with PNS, a mixture of $\mathrm{KNO}_{3}$ and surfactant was applied biweekly to mature pecan trees from April through August with an air-blast speed sprayer. This treatment window corresponds to the period in which the spring population excludes the autumn population peak of these aphids. The window also covers the time of fruit expansion, but not kernel filling. Potassium nitrate was evaluated at $0.5 \%$ and $1.0 \%$ (w/w), using a low-cost trisodium phosphate surfactant (Sears detergent; Sears, Chicago). Sprays were applied with a FMC-1057 (Chicago) speed sprayer with a pecan volute delivering $\approx 1122$ liters $\cdot$ ha $^{-1}$, which is typical of that performed in commercial pecan operations.

\section{Materials and Methods} peak occurs for the "yellow-type" aphids but
The orchard was comprised of 80-year-old, alternate-bearing 'Moneymaker' trees under commercial-like management for at least the previous 25 years and had leaf $\mathrm{K}$ and $\mathrm{N}$ levels well above the sufficiency baseline established by the Georgia Cooperative Extension Service (commercial orchards in which PNS foliar sprays are used are typically well within the sufficiency range for $\mathrm{K}$ and $\mathrm{N}$ ).

The experiment testing the hypothesis that PNS foliar sprays increase nut production, kernel quality, or both consisted of a randomized complete-block (RCB) design comprised of three treatments in each of 20 blocks with each experimental unit consisting of four adjacent trees $(n=240)$. The 85 -year-old trees were located in a 15-ha orchard and were growing at an $18 \times 18-\mathrm{m}$ square spacing. Treatments consisted of 1) an unsprayed control in which trees did not receive PNS sprays; 2) sprays of $0.5 \% \mathrm{KNO}_{3}$ plus $0.15 \%$ trisodium phosphate surfactant (w/w); and 3) sprays of $1.0 \% \mathrm{KNO}_{3}$ plus $0.15 \%$ trisodium phosphate surfactant $(\mathrm{w} / \mathrm{w})$. Treatments were applied biweekly from April to August for four consecutive years. No other pesticide or nutritional sprays were applied, except for 1naphthalenyl methylcarbamate (carbaryl) (Rhone-Poulenc, Philadephia) for pecan weevil [Curculio caryae (Horn)] in late August after the termination of the K treatment sprays. This 'Moneymaker' orchard exhibits little to nopecan scab [Cladosporium caryigenum (Ell. and Langl.) Gottwald], thus scab sprays were not applied. For statistical analysis purposes, the treatments were treated as discrete (since surfactant level did not vary) variables and were analyzed by analysis of variance (ANOVA) using Tukey's Studentized Range Test to compare treatments (SAS-PC).

The $\mathrm{KNO}_{3}$ source was a commercial product (K-Power; Cedar Chemical Corp., Seffner, Fla.) consisting of $13.75 \%$ total N (in nitrate form) and $44.50 \% \mathrm{~K}$ in soluble potash $\left(\mathrm{K}_{2} \mathrm{O}\right)$ and possessing a low salt index, with essentially no $\mathrm{Cl}, \mathrm{Na}$, or $\mathrm{S}$. The tank mix of PNS characteristically exhibited a $\mathrm{pH}$ ranging from 8 to 10 . Treatments were applied so as to minimize spray drift.

The influence of treatments on production and quality was determined annually for 4 years by harvesting nuts in October from the two centermost trees of the four tree plots. Nut weight per tree, kernel percentage, and nut volume were measured.

Leaf $K$ concentration. The influence of treatments on leaf $\mathrm{K}$ levels was determined annually for 4 years by sampling foliage in late July. Sampling protocol consisted of collecting the middle leaflet pairs of the middle compound leaf of each of 10 terminal shoots from around the midcrown of each of the two centermost trees within each experimental unit. Leaflets were soaked and agitated ( $2 \mathrm{~min})$ and rinsed (1 min) in deionized water, immediately dried at $55 \mathrm{C}$, and ground for analysis. Ground leaf material $(500 \mathrm{mg})$ was dissolved in $\mathrm{HCl}$ and analyzed for $\mathrm{K}$ using a Spectraspan $\mathrm{V}$ Atomic-Emission Spectrometer (DCP) (Beckman, Irvine, Calif.). Statistical analysis was as described above. 
Leafphotosynthesis. The influence of PNS sprays on pecan leaf carbon exchange was estimated by measuring $\mathrm{CO}_{2}$ exchange of treated leaflets. Gas exchange was measured using a LI-COR 6000 Portable Photosynthetic System (LI-COR, Lincoln, Neb.). Evaluated treatments were 1) unsprayed control, 2) surfactant at $0.15 \%$ solution in water $(\mathrm{w} / \mathrm{w}), 3)$ $\mathrm{KNO}_{3}$ at $1.0 \%$ solution in water $\left.(\mathrm{w} / \mathrm{w}), 4\right)$ $1.0 \% \mathrm{KNO}_{3}$ plus $0.15 \%$ surfactant in water (w/ w), 5) Safer (Newton, Mass.) insecticidal soap at $0.5 \%(\mathrm{v} / \mathrm{v})$, and 6) Attack (Ringer Corp., Minneapolis) insecticidal soap at $0.5 \%(\mathrm{v} / \mathrm{v})$. The two insecticidal soaps are also surfactants and were included as internal controls. Carbon exchange rate was estimated using a 1-liter leaf chamber. Treatments were applied to five apical sunleaf-type leaflets from the apical compound leaf of five terminal shoots located $\approx 10 \mathrm{~m}$ above ground. Treatments were applied with a hand sprayer until leaf drip. Photosynthetic measurements were made before spraying and again on the same leaflets 1, 5, and 12 days after spraying.

Measurements were made between 10:00 $\mathrm{AM}$ and solar noon at light levels $>1400$ $\mu \mathrm{mol} \cdot \mathrm{m}^{-2} \cdot \mathrm{s}^{-1}$ photosynthetic photon flux and at ambient $\mathrm{CO}_{2}$ levels (ranging from $\approx 320$ to $380 \mu 1 \cdot$ liter $^{-1}$ ). Leaf temperature typically increased $<0.3 \mathrm{C}$ during the measurement period.

Yellow aphid populations. The influence of PNS sprays on yellow aphid populations [common terminology referring to blackmargined aphids (Monellia caryella (Fitch)] and the yellow pecan aphid [Monelliopsis pecanis (Bissell)] was estimated in two studies. The first study was within the constraints of the above "production and kernel quality" study where combined populations of blackmargined and yellow pecan aphids were recorded either 1 or 2 days after each of the spray applications throughout the study period. Aphids were counted on the centermost two trees of each four-tree experimental unit on each of three terminal shoots sampled at the exterior of the midcanopy level on the east-, south-, and west-facing sectors. Statistical analysis was as with the above-described production and kernel quality study.

After aphid-associated treatment differences were observed in the first study, a second study was conducted to investigate the effects contributed by the various components of the PNS treatment. This study incorporated air-blast foliar sprays to mature trees with high aphid populations. Treatments were 1) unsprayed (C), 2) air-blast spray of water (AB), 3) air-blast spray of water with $0.5 \%$ $\left.\mathrm{KNO}_{3}(\mathrm{AB}+\mathrm{W}), 4\right)$ air-blast spray of water with $0.15 \%$ Sears surfactant $(A B+S), 5)$ airblast spray of water with $0.5 \% \mathrm{KNO}_{3}$ plus $0.15 \%$ Sears surfactant $(A B+W+K+S)$. Potassium nitrate and surfactant percentages were based on weight : weight. Trees were sprayed with the same sprayer as described in the production and kernel quality experiment. Yellow-type pecan aphids were counted 1 day after spraying by sampling from all leaves on three terminal shoots from the east, south, and west sectors of the trees (nine terminals total). The design was a RCB consisting of 10 blocks, with a buffer tree between blocks $(n=50$ trees). The study was run twice with similar results; however, only results of the second test are reported. Statistical analysis was by ANOVA using the Waller-Duncan k-ratio $t$ test to separate means.

\section{Results}

Nut production and kernel quality. PNS treatments did not affect the three defined yield characteristics, in any of the four years $(\alpha \leq 0.10$; data excluded; nuts per tree ranged from 2 to $12 \mathrm{~kg}$ in "off" years and 31 to $106 \mathrm{~kg}$ in "on" years; nut volume ranged from 6 to 10 $\mathrm{cm}^{3}$; and percentage kernel ranged from $44 \%$ to $50 \%$ ). Because we used 120 trees in a 20block RCB structure, the experiment likely was sufficiently sensitive to detect any treatment differences that would have been of any practical importance to a pecan grower using such sprays on trees with foliar $\mathrm{K}$ exceeding $\approx 0.8 \%$ (within sufficiency range). Therefore, when compared to the unsprayed control, neither of the two PNS treatments exhibited a detectable positive or negative trend on nut production, kernel percentage, or nut volume in either of the two on or off production years of the 4-year study.

Leaf $K$ concentration. Foliar-applied K increased leaf $\mathrm{K}$ concentration $(\alpha \leq 0.05)$ in only the on year of 1989 — and then only with the $0.5 \% \mathrm{KNO}_{3}$ plus $0.15 \%$ surfactant (Table 1). When assessed over the length of the study, there was, however, a slight trend of higher leaf $\mathrm{K}$ concentration with increasing $\mathrm{K}$ application amounts; however, only $1.0 \% \mathrm{KNO}_{3}$ resulted in statistical evidence of producing a higher leaf K concentration, which was only $31 \mathrm{ppm}$ above that in leaves of the unsprayed control.

Net photosynthesis. Net photosynthetic rates of mature and healthy leaves were not influenced by $\mathrm{KNO}_{3}$, Sears surfactant, or a combination of both from 1 to 12 days after treatment (Table 2). In contrast, two internal controls consisting of surfactants with known insecticidal activity (although not used by

Table 1. Concentration of $\mathrm{K}$ in leaves as a result of biweekly (April through August) foliar sprays with $\mathrm{KNO}_{3}$ and surfactant.

\begin{tabular}{lccccc}
\hline & \multicolumn{5}{c}{ K concn (\%) during early August } \\
\cline { 2 - 6 } Treatment $^{\mathrm{z}}$ & 1987 & 1988 & 1989 & 1990 & Mean \\
\hline Unsprayed control & $0.95 \mathrm{a}^{\mathrm{y}}$ & $1.02 \mathrm{a}$ & $0.79 \mathrm{~b}$ & $1.00 \mathrm{a}$ & $0.93 \mathrm{~b}$ \\
$\mathrm{AB}+\mathrm{W}+0.5 \% \mathrm{~K}+0.15 \% \mathrm{~S}$ & $0.91 \mathrm{a}$ & $1.10 \mathrm{a}$ & $0.82 \mathrm{a}$ & $1.00 \mathrm{a}$ & $0.94 \mathrm{ab}$ \\
$\mathrm{AB}+\mathrm{W}+1 \% \mathrm{~K}+0.15 \% \mathrm{~S}$ & $0.89 \mathrm{a}$ & $1.08 \mathrm{a}$ & $0.79 \mathrm{~b}$ & $1.00 \mathrm{a}$ & $0.96 \mathrm{a}$
\end{tabular}

${ }^{\mathrm{z}} \mathrm{AB}+\mathrm{W}+0.5 \% \mathrm{~K}($ or $1.0 \% \mathrm{~K})+0.15 \% \mathrm{~S}$ is air-blast spray of water containing $0.05 \%$ (or $1.0 \%$ ) $\mathrm{KNO}_{3}$ and $0.15 \%$ surfactant (Sears detergent).

'Means separated in columns differ at $\alpha \leq 0.05$ by Tukey's Studentized Range Test.

Table 2. Influence of single foliar spray of $\mathrm{KNO}_{3}$ and surfactant on net photosynthesis (Pn) of pecan leaves.

\begin{tabular}{lrrr}
\hline & \multicolumn{3}{c}{ Pn (\% of pretreatment Pn rates) } \\
\cline { 2 - 4 } & \multicolumn{3}{c}{ Days after treatment } \\
\cline { 2 - 4 } Spray treatment & $112 \mathrm{a}^{\mathrm{z}}$ & 5 & 12 \\
\hline Unsprayed control & $117 \mathrm{a}$ & $130 \mathrm{a}$ & $131 \mathrm{a}$ \\
Surfactant $(0.15 \% \mathrm{w} / \mathrm{w})$ & $105 \mathrm{a}$ & $131 \mathrm{a}$ & $103 \mathrm{a}$ \\
$\mathrm{KNO}_{3}(1.0 \% \mathrm{w} / \mathrm{w})$ & $104 \mathrm{a}$ & $106 \mathrm{a}$ & $105 \mathrm{a}$ \\
$\mathrm{KNO}_{3}(1.0 \% \mathrm{w} / \mathrm{w})+$ surfactant $(0.15 \%)$ & $23 \mathrm{~b}$ & $32 \mathrm{~b}$ & $35 \mathrm{~b}$ \\
Insecticidal soap (Safer) & $36 \mathrm{~b}$ & $57 \mathrm{~b}$ & $63 \mathrm{ab}$ \\
Insecticidal soap (Attack) & & & $141 \mathrm{a}$ \\
\hline
\end{tabular}

${ }^{2}$ Means separated in columns differ at $\alpha \leq 0.05$ by Tukey's Studentized Range Test. 
Table 3. Effectiveness of air-blast sprays of $\mathrm{KNO}_{3}+$ surfactant for suppressing early season populations of yellow-type pecan aphids in an orchard of 85-year-old 'Moneymaker' pecan trees. Sprays were generally biweekly from late April to early August, with aphid counts being made 1 day after spraying.'

\begin{tabular}{|c|c|c|c|c|c|c|c|c|c|c|c|c|}
\hline \multirow[b]{3}{*}{ Treatment $^{x}$} & \multicolumn{12}{|c|}{ Mean aphid population level per week of month (aphids/compound leaf) ${ }^{y}$} \\
\hline & \multirow{2}{*}{$\begin{array}{c}\text { April } \\
1 \text { st }\end{array}$} & \multicolumn{3}{|c|}{ May } & \multicolumn{4}{|c|}{ June } & \multicolumn{3}{|c|}{ July } & \multirow{2}{*}{$\frac{\text { August }}{1 \mathrm{st}}$} \\
\hline & & 1 st & 2nd & $3 \mathrm{rd}$ & 1 st & 2nd & $3 \mathrm{rd}$ & 4th & 1 st & 2nd & 3 rd & \\
\hline & & & & & 1987 & & & & & & & \\
\hline Unsprayed control & $13.2 \mathrm{a}^{\mathrm{w}}$ & $1.1 \mathrm{a}$ & $0.3 \mathrm{a}$ & $0 \mathrm{a}$ & $0.1 \mathrm{a}$ & $0.1 \mathrm{a}$ & $0.4 \mathrm{a}$ & $0.6 \mathrm{a}$ & $1.3 \mathrm{a}$ & $0.9 \mathrm{a}$ & $0 \mathrm{a}$ & $0.9 \mathrm{a}$ \\
\hline $0.5 \% \mathrm{KNO}_{3}+$ surfactant & $7.3 \mathrm{~b}$ & $0.5 \mathrm{~b}$ & $0.3 \mathrm{a}$ & $0 \mathrm{a}$ & $0.1 \mathrm{a}$ & $0.0 \mathrm{~b}$ & $0.2 \mathrm{~b}$ & $0.2 \mathrm{~b}$ & $1.1 \mathrm{a}$ & $0.4 \mathrm{~b}$ & $0 \mathrm{a}$ & $0.2 \mathrm{a}$ \\
\hline $1.0 \% \mathrm{KNO}_{3}+$ surfactant & $6.2 \mathrm{~b}$ & $0.5 \mathrm{~b}$ & $0.1 \mathrm{a}$ & $0 \mathrm{a}$ & $0 \mathrm{a}$ & $0.0 \mathrm{~b}$ & $0.2 \mathrm{~b}$ & $0.2 \mathrm{~b}$ & $1.0 \mathrm{a}$ & $0.3 \mathrm{~b}$ & $0 \mathrm{a}$ & $0.1 \mathrm{~b}$ \\
\hline & & & & & 1988 & & & & & & & \\
\hline Unsprayed control & $---^{v}$ & --- & $1.6 \mathrm{a}$ & $0.3 \mathrm{a}$ & $0.1 \mathrm{a}$ & $0.1 \mathrm{a}$ & $0 \mathrm{a}$ & $0.1 \mathrm{a}$ & $1.7 \mathrm{a}$ & $1.5 \mathrm{a}$ & $7.2 \mathrm{a}$ & $1.8 \mathrm{a}$ \\
\hline $0.5 \% \mathrm{KNO}_{3}+$ surfactant & --- & --- & $1.7 \mathrm{a}$ & $0.2 \mathrm{a}$ & $0.1 \mathrm{a}$ & $0 \mathrm{a}$ & $0 \mathrm{a}$ & $0 \mathrm{a}$ & $0.5 \mathrm{a}$ & $1.9 \mathrm{a}$ & $4.6 \mathrm{~b}$ & $1.2 \mathrm{~b}$ \\
\hline $1.0 \% \mathrm{KNO}_{3}+$ surfactant & --- & --- & $1.2 \mathrm{a}$ & $0.2 \mathrm{a}$ & $0.1 \mathrm{a}$ & $0 \mathrm{a}$ & $0 \mathrm{a}$ & $0 \mathrm{a}$ & $0.2 \mathrm{~b}$ & $1.6 \mathrm{a}$ & $5.2 \mathrm{~b}$ & $0.8 \mathrm{~b}$ \\
\hline
\end{tabular}

${ }^{2}$ Treatment means are presented for each weekly/monthly date for 1987 and 1988. Data for 1989 and 1990 are not presented because differences were not as pronounced due to abnormally low pecan aphid populations. The experimental design was a randomized complete block comprised of 20 blocks of two treatments and a nontreated control, all three consisting of four trees per experimental unit $(\mathrm{n}=240$ trees). Aphid counts are comprised of a mixture of two yellow aphid apecies (yellow pecan aphid and blackmargined aphids) consisting of all developmental classes. Black pecan aphids are not included in the above analysis. Counts were made on three terminal shoots from each of three tree locations consisting of a total of as many as 72 compound leaves sampled at about one-third crown level from three sections of the canopy.

${ }^{\mathrm{y}}$ Compound leaf is typically comprised of from seven to 15 leaflets.

${ }^{x}$ Spray treatments consist of unsprayed control, $0.5 \%(\mathrm{w} / \mathrm{w})$ surfactant, and $1.0 \%(\mathrm{w} / \mathrm{w}) \mathrm{KNO}_{3}+0.15 \%$ (w/w) surfactant, with the surfactant being Sears detergent. "Mean separation within columns at $\alpha \leq 0.05$ by Tukey's Studentized Range Test.

${ }^{v}$ Dates when aphid populations were subjectively assessed but not objectively measured; hence, populations were judged to be too low to derive meaningful counts.

evaluation on mature alternately bearing 'Moneymaker' trees, the associated suppression of aphid populations is evidence that such treatments have the potential for increasing yields in orchards with high populations of yellow-type aphids. This possibility is supported by observations of detrimental effects of high populations of yellow-type aphids on nut production (Dutcher et al., 1984; Stone and Watterson, 1981; Tedders and Wood, 1985), kernel quality (Tedders and Wood, 1985; Wood et al., 1987), and leaf photosynthesis (Wood et al., 1985). The absence in our study of detectable treatment effects on yield characteristics might be attributed to the low yellow-type population levels present during the four years of study; therefore, aphid levels might not have been high enough to measurably influence the yield-related characteristics investigated. The deletion of fungicide sprays from the treatment protocol was not a confounding factor influencing measured characteristics because 'Moneymaker' exhibits no disease problems at the study location. Claims by growers of treatment effects may, therefore, be attributable to the influence of spray treatments on yield characteristics via aphid population suppression rather than via enhancement of $\mathrm{K}$ (or possibly $\mathrm{N}$ ) nutrition or photosynthesis. The minimal or no elevation in leaf $\mathrm{K}$ in our study is in general agreement with observations by Smith et al. (1987) that foliar-applied $\mathrm{KNO}_{3}$ was not effective in supplying $\mathrm{K}$ to the foliage.

Because of the apparently high demand for $\mathrm{K}$ (and $\mathrm{N}$ ) by alternate-bearing trees (Krezdorn, 1955; Wood, 1986) during on years, it could be argued that, if PNS influences yield characteristics of alternate-bearing cultivars, it likely would have been exhibited in our study because 'Moneymaker' is a strong alternate bearer. Similarly, there was also no evidence that several foliar sprays per growing season would materially increase leaf $\mathrm{K}$ content or influence leaf net photosynthesis. While treatment effects on foliar $\mathrm{N}$ content were not quantified, the lack of yield differences is evidence that spray treatments had little or no practical influence on $\mathrm{N}$ levels. While this response might not be true for trees with subsufficiency $\mathrm{K}$ or $\mathrm{N}$ levels, such low levels are not likely to be representative of commercial orchards and this management strategy (low K or $\mathrm{N}$ levels) would have little or no practical importance. PNS sprays resulted in no apparent detrimental effect on foliage, except for an occasional leaf burn, at the drip point of leafs $\left(\approx 3 \mathrm{~mm}^{2}\right.$ of damaged tissue), which became visible near the end of July.

The observation that yellow-type aphid populations can be suppressed, especially when high, by either $\mathrm{AB}+\mathrm{W}$ alone or even more with $\mathrm{K}+\mathrm{S}$ added, raises the possibility that these treatments may be useful for developing alternative aphid management strategies. A potential problem with PNS sprays is that the resulting high solution $\mathrm{pH}$ (up to 10) presents the potential for deactivation of active ingredients by alkaline hydrolysis if tank-mixed with susceptible pesticides; hence, a pH of 5 to 6 is typically maintained when used with fungicides.

These data illustrate the importance of using air-blast and water controls in aphicide trials if the formulation effect is to be quantified. Circumstantial evidence is also provided that certain metallic salts may possibly sup-

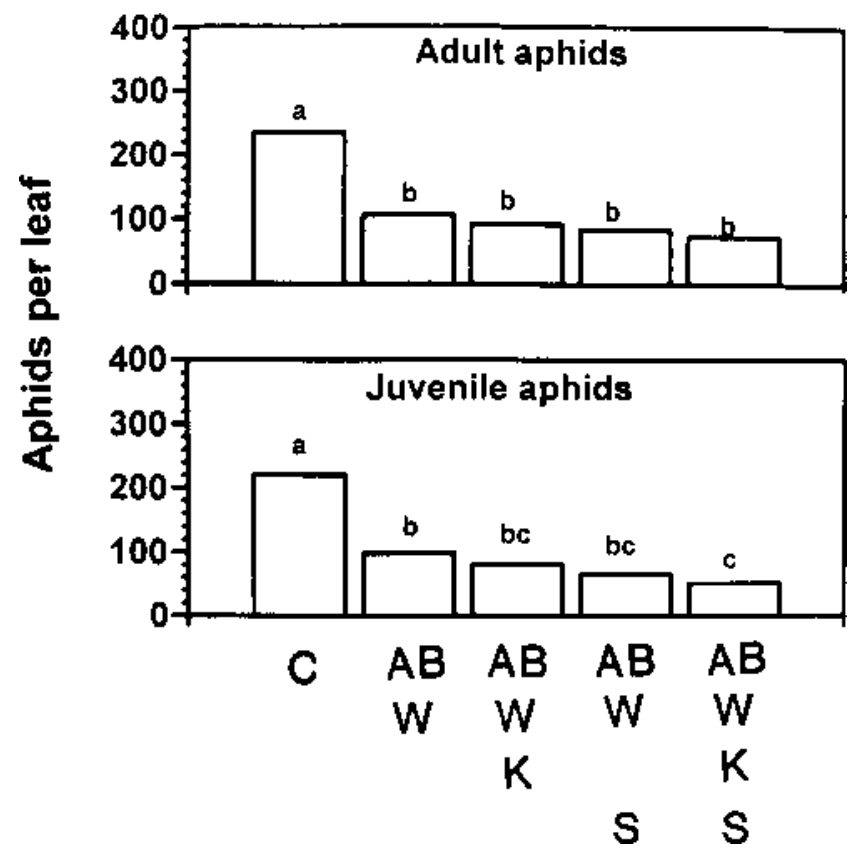

Fig. 1. Influence of air-blast foliar sprays, with and without $\mathrm{KNO}_{3}$, surfactant, or both, on adult and juvenile yellow-type pecan aphid populations on pecan foliage 1 day after spraying. The study consisted of five spray treatments [unsprayed control (C); air-blast spray with water $(\mathrm{AB}+\mathrm{W})$; air-blast spray with water and $0.5 \% \mathrm{KNO}_{3}(\mathrm{AB}+\mathrm{W}+\mathrm{K})$; air-blast with water and $0.15 \%$ surfactant (trisodium-phosphate-based Sears detergent; $\mathrm{AB}+\mathrm{W}+\mathrm{S})$; and air-blast with water and $\mathrm{KNO}_{3}$ and surfactant $\left.(\mathrm{AB}+\mathrm{W}+\mathrm{K}+\mathrm{S})\right]$. Mean separation within aphid class by Waller-Duncan k-ratio $t$ test at $\alpha \leq 0.05$. 


\section{Crop Production}

press yellow-type aphid populations; therefore, other heavy metal salts may have greater efficacy and merit study. Additionally, the differential influence of the surfactants used in our study on net photosynthesis underscores the potential for long-term suppression of leaf photosynthetic activity, and possibly an associated yield loss, if a harmful surfactant is used.

This study provides evidence that the practice of applying early season foliar sprays of PNS may have merit as an alternative means of suppressing yellow-type aphid populations, but is likely not justifiable if used solely as a means of increasing yield via enhancing $\mathrm{K}$ nutrition. Efficacy of PNS as a late-season management tool merits investigation, since it is during this time that the fruit is filling and the yellow-type aphid population can be especially high.

\section{Literature Cited}

Condrashoff, S. 1986. Insecticidal soaps: A pest control alternative. Agrologist 15:18-19.

Dutcher, J., R. Worley, J. Daniell, R. Moss, and K. Harrison. 1984. Impact of six insecticide-based arthropod management strategies on pecan yield. Environ. Entomol. 13:1644-1653.

Hastings, F.L., F.P. Hain, A. Mangini, and W.T. Huxster. 1986. Control of the balsam woolly adelgid (Homoptera: Adelgidae) in Fraser fir Christmas tree plantations. J. Econ. Entomol. 79:1676-1680.

Klezdorn, A.A. 1955. The nutrient status of pecan leaves in relation to alternate bearing. Proc. Texas Pecan Growers Assn. 34:43-53.

Miller, F.D. 1989. The use of horticultural oils and insecticidal soaps for control of insect pests of amenity plants. J. Aboric. 15(11):257-262.

Moore, W.S., J.C. Profits, and C.S. Koehler. 1979. Soaps for home landscape insect control. Calif. Agr. 33(6):13-14.

Moorthy, P.N.K. and K. Srinivassan. 1989. Petiolemining thresholds and potassium, chloride sprays for management of bean fly (Diptera: Agromyzidae) in snap beans and cowpea. J. Econ. Entomol. 81:246-250.

Parry, W.H., I.D. Edwards, and T.A.R. James. 1989. Chemical control of sycamore aphid, Drepanosiphum plantoidis (Schr.) with organophosphorus and soap insecticides. Crop Protection 8:30-36.

Smith, M. 1991. Pecan nutrition, p. 152-158. In: B.W. Wood and J.A. Payne (eds.). Pecan husbandry: Challenges and opportunities. First Natl.
Pecan Wkshp. Proc. U.S. Dept. of Agr--Agr. Res. Serv, ARS-86.

Smith, M.W., B.C. Cotten, and P.L. Agar. 1987. Foliar potassium sprays on adult pecan trees. HortScience 29:82-84.

Stone, J.D. and G.P. Watterson. 1981. Impact of blackmargined aphid control on yield in western irrigated pecan orchards with systemic insecticides. J. Econ. Entomol. 74:741-744.

Tedders, W.L. and B.W. Wood. 1985. Estimate of the influence of feeding by Monelliopsis pecanis and Monellia caryella on the fruit, foliage, carbohydrate reserves, and tree productivity of mature 'Stuart' pecans. J. Econ. Entomol. 78:642-646.

Wood, B.W. 1986. Cold injury susceptibility of pecan as influenced by cultivar, carbohydrates, and crop load. HortScience 21:285286.

Wood, B.W., W.L. Tedders, and J.D. Dutcher. 1987. Energy drain by three pecan aphid species (Homoptera: Aphididae) and their influence inshell pecan production. Environ. Entomol. 16:1045-1056.

Wood, B.W., W.L. Tedders, and J.M. Thompson. 1985. Feeding influence of three pecan aphid species on carbon exchange and phloem integrity of seedling pecan foliage. J. Amer. Soc. Hort. Sci. 110:393-397. 